Original Research Paper

\title{
The Role of Receptor Activator of Nuclear Factor Kappa B (RANK) and Receptor Activator of Nuclear Factor Kappa B Ligand (RANKL) in Osteoporosis Risk: Gene Polymorphism and Soluble RANKL Level in Indonesia Post-Menopausal Women
}

\author{
${ }^{1}$ Luluk Yunaini, ${ }^{1}$ Dwi Anita Suryandari, ${ }^{2}$ Linda Kusdhany, \\ ${ }^{3}$ Mala Kurniati, ${ }^{4}$ Indhina Reihannisha and ${ }^{2}$ Elza Ibrahim Auerkari \\ ${ }^{1}$ Department of Medical Biology, Faculty of Medicine, Universitas Indonesia, Jakarta 10430, Indonesia \\ ${ }^{2}$ Department of Oral Biology, Faculty of Dentistry, Universitas Indonesia, Jakarta 10430, Indonesia \\ ${ }^{3}$ Faculty of Medicine, Universitas Malahayati, Lampung 35153, Indonesia \\ ${ }^{4}$ Master of Biomedical Science, Faculty of Medicine, Universitas Indonesia, Jakarta 10430, Indonesia
}

\author{
Article history \\ Received: 10-08-2018 \\ Revised: $16-08-2018$ \\ Accepted: 27-09-2018 \\ Corresponding Author: \\ Luluk Yunaini \\ Department of Medical \\ Biology, Faculty of Medicine, \\ Universitas Indonesia, Jakarta \\ 10430, Indonesia \\ Tel: $+62-21-31930379$ \\ Fax: +62-21-31907281 \\ Email: luluk.yunaini@ui.ac.id
}

Abstract: Hormonal changes in postmenopausal women may increase osteoclastogenesis that can lead to increased risk of osteoporosis. Receptor Activator of Nuclear factor Kappa B (RANK) and Receptor Activator of Nuclear factor Kappa B Ligand (RANKL) have an important role in osteoclastogenesis that involve in the regulation of bone resorption. In this study, we analyzed the Single Nucleotide Polymorphism (SNPs) within the RANK/RANKL gene and the associated sRANKL level to assess the risk of osteoporosis in postmenopausal Indonesian women. Research was conducted as case control study that involved 210 postmenopausal Indonesian women. 105 of the women were classified as osteoporosis and 105 as normal. Genetic analysis was performed by PCR-RFLP. BMD was measured by Dual energy X-ray Absorptiometry (DXA) and the RANKL serum level was determined by ELISA. For statistical analysis, Chi-square testing, Kruskal Wallis testing, Mann-Whitney $U$ testing and odds ratio testing were mainly applied, with a significance level of $p<0.05$. Genotype frequencies of RANK and RANKL polymorphism were compared between osteoporosis and normal group. Statistical analysis showed significant difference between the two group for genetic $(\mathrm{p}<0.05)$ and allele $(\mathrm{p}<0.05)$ of RANK gene (rs121908659) polymorphism. The elevated odd ratio suggests an increased risk (4.83-folds) to osteoporosis with the genotype CG in compare with genotype GG. No significant difference in RANK (rs1805034) and RANKL (rs9594759) in genotypes and allotypes. Even though there were no significant differences in the RANKL genotype, but we found that CT genotype was protective factor than CC genotypes. sRANKL levels in the RANKL genotype was significantly different $(\mathrm{p}<0.05)$, with RANKL level of TT genotype was higher than CC/CT genotype. Genotype and allele frequencies of RANK polymorphism (rs121908659) have been found to be associated with an elevated risk to osteoporosis in postmenopausal Indonesian women. Moreover, polymorphism of RANKL at the SNP location rs9594759 was significantly associated with level of sRANKL.

Keywords: RANK, RANKL, sRANKL Level, Osteoporosis, Postmenopausal 


\section{Introduction}

Menopause is a natural aging process in a woman's life that is marked by physiological termination of menstruation cycle (Raisz, 2005; Nelson, 2008). Postmenopausal women have a higher risk in osteoporosis and cardiovascular, which is considered as a result of the decrease in estrogen level (Bell, 2003; Finkelstein et al., 2008). Estrogen hormone prevents bone resorption through different aspect in bone marrow and bone cells, which in turn will decrease osteoclastogenesis, increase osteoclast apoptosis and decrease the mature osteoclast ability of bone resorption (Weitzmann and Pacifici, 2006).

Studies on animal model have been done to obtain information on the mechanisms of bone mineral density in aging process, estrogen deficiency condition, or on effect of various pathological conditions and disease. A study on animal model using mice that have undergone ovariectomy process showed increase of trabecular bone resorption, accompanied by decreased bone strength after the estrogen level decreased (Lacey et al., 1998; Bitto et al., 2008; Kearns et al., 2008). The decrease of estrogen level leads to the increase of osteoclastogenesis (Bell, 2003).

Studies on osteoclastogenesis developed after the discovery of the role of Osteoprotegerin (OPG), Receptor Activator of Nuclear factor $\kappa B$ (RANK) and Receptor Activator of Nuclear factor $\kappa B$ Ligand (RANKL) in bone metabolism process. All three substances have roles in bone cell control (Boyle et al., 2003; Eghbali-Fatourechi et al., 2003). Osteoclast activation occurs by influence of RANKL affinity towards RANK, whereas OPG takes role as RANK competitor receptor which can bond with RANKL, avoiding RANKL bonding with RANK, therefore prohibiting bone resorption (Srivastava et al., 2001; McClung, 2007; Kearns et al., 2008). Study on mice as animal model performed by Srivastava et al. (2001) reported that the increase of osteoclastogenesis is due to the increase of response of bonding RANK and RANKL (Giroux and Rousseau, 2009).

RANKL is one of the Tumor Necrosis Factor (TNF) family. It is also known as TNF-Related Activationinduced Cytokine (TRANCE), Osteoprotegerin Ligand (OPGL) and Osteoclast Differentiation Factor (ODF). RANK is the receptor of RANKL. It has a critical role in bone remodeling and also essential in the development and activity of osteoclasts (Manolagas, 2000; Jones et al., 2002; Boyle et al., 2003; Teitelbaum, 2004). Differentiation of progenitor hemopoietic depends on RANK that is located on the cell membrane of osteoclast cell. RANKL is expressed on membrane surface of osteoblastic stromal cells. Furthermore, RANKL will be binds to RANK on the surface of osteoclast progenitor cell to stimulate cell differentiation (Jilka, 2001).

RANK protein consists of 616 amino acids that are included in the type I trans-membrane protein. RANK consists of cistein-abundant extracellular. RANK protein on mice and human have $70 \%$ similarity. Northern blot analysis indicates that $4,5 \mathrm{~kb}$ of human mRNA RANK are expressed in almost all tissues (Guerrini et al., 2008; Styrkarsdottir et al., 2008).

RANKL cDNA clones have an open reading frame that encodes a 317 amino acid type II transmembrane protein. Intracellular domain consists of 48 amino acid terminus while the transmembrane domain is composed of 24 amino acids hydrophobic. Carboxy-terminal residue has significant homology to the TNF ligand family members. RANKL associated into a homotrimer. Homotrimer is similar to other TNF molecule. It has four loops with a unique surface that is required for full activation of RANK. RANKL was first identified as a transmembrane protein. But later on it was also found in different form or as soluble RANKL. The soluble RANKL is secreted by the helper T cells or disengaged from the position of the membrane by metalloproteinases. The soluble RANKL also has a role in osteoklastogenesis (Rubin and Greenfield, 2005).

Genetic variety on population regulates bone mass density, especially on post-menopausal women (Giroux and Rousseau, 2009; Wang et al., 2014; Tu et al., 2015). Decrease of bone mass density caused by osteoclastogenesis increase is influenced by the activity of RANKL/RANK/OPG. Genetic variety on RANK, RANKL and OPG genes have correlation with bone mass density (Bonfá et al., 2015; Tu et al., 2015). This study is focused on the analysis of RANK/RANKL genetic variety and RANKL level on post-menopausal women in Indonesia.

Single Nucleotide Polymorphism (SNP) analyzed in this research were RANK gene on rs121908659 and rs1805034, whereas RANKL gene on rs9594759. In SNP positioned r121908659, G base is converted to C base, causing the transformation of Glicine (Gly) amino acid into Arginine (Arg) on the $53^{\text {rd }}$ position. rs $1805034(\mathrm{C} / \mathrm{T}$ ) causing alteration of Alanin (Ala) into Valin (Val) on 192rd position (Koh et al., 2007). Position of rs9594759 in upstream region of RANKL gene, $\mathrm{C}$ base is converted to T base (Styrkarsdottir et al., 2008). Polymorphism of RANKL gene in the upstream regions can affect the transcription process and implicates the formation of proteins and osteoclastogenesis. Therefore, the mutation in the upstream regions can be observed in the protein levels. This research will analyze the association between genetic variety on RANK/RANKL and sRANKL level with the osteoporosis risk on the population of postmenopausal women in Indonesia. 


\section{Materials and Methods}

\section{Subjects}

Sample used were DNA isolate obtained from 210 post-menopausal women (Approval letter No. 159/H2.F1/ETIK/2013). DNA isolate were obtained from post-menopausal women within the age range of 50-75 years old, Deutero-Malay race group, healthy physical condition without systemic disease such as diabetes mellitus, bronchial asthma, osteomalacia, cancer and tuberculosis. Subjects were not undergoing medicinal therapy such as steroids, osteoporosis therapy medicines, anticoagulant, anti convulsion, never undergone ovarian removal operation, not on a diet program and filled informed consent. DNA on osteoporosis group requires extra conditions: T-score under -2.5 , while non-osteoporosis group were obtained from post-menopausal non-osteoporosis women's DNA whose T-score are larger than -1 .

\section{Fragment Amplification of Target DNA}

Fragment Amplification DNA was performed with Polymerase Chain Reaction (PCR) method using Gotaq $^{\mathrm{TM}}$ PCR Core System kit (Promega). Volume of each reagent is $50 \mu \mathrm{L}$, consists of $100 \mathrm{ng}$ genomic DNA, $1 \mu \mathrm{M}$ each of primer oligonucleotide, 1x Green Gotaq, $2.5 \mathrm{mM} \mathrm{MgCl}$, $200 \mathrm{mM}$ dNTP mix and $1.25^{\mathrm{U}}$ Tag DNA polymerase. Primer used for DNA target amplification are described in Table 1.

DNA samples were amplified for 35 cycles, with initial denaturation on $94^{\circ} \mathrm{C}$ for $5 \mathrm{~min}$, continued into a cycle which consists of denaturation on $94^{\circ} \mathrm{C}$ for $30 \mathrm{sec}$, annealing on $47-62^{\circ} \mathrm{C}$ (Table 1) for $30 \mathrm{sec}$ dan elongation on $72^{\circ} \mathrm{C}$ for $30 \mathrm{sec}$. At the end of the cycle, extension time was prolonged on $72^{\circ} \mathrm{C}$ for $7 \mathrm{~min}$.
Amplification results were separated using electrophoresis on $2 \%$ agarose gel with 90 Voltage for $60 \mathrm{~min}$. The lengths of target DNA from the PCR are shown in Table 1.

\section{Restriction Fragment Length Polymorphism (RFLP)}

Restriction fragment were performed using $1 \mathrm{U}$ of restriction enzyme (New England Biolabs) into a vial with $1 \mu \mathrm{g}$ of DNA fragment acquired from amplification process, $2 \mu \mathrm{L}$ of buffer solution $\mathrm{RE} 10 \mathrm{X}$ and $\mathrm{ddH}_{2} \mathrm{O}$ up to $20 \mu \mathrm{L}$, incubated in water bath on optimal temperature for each restriction enzyme (Table 2.) for $4 \mathrm{~h}$. Restriction enzyme was inactivated by incubation on inactive temperature for each restriction enzyme for $20 \mathrm{~min}$. DNA fragment was analyzed in $3 \%$ agarose gel in TAE $1 \mathrm{x}$ on 90 Voltage for $60 \mathrm{~min}$. Restriction fragment result using restriction enzymes are shown in Table 2.

\section{SRANKL Content Measurement of sRANKL Levels using ELISA Method}

This examination used a sandwich ELISA assay sRANKL which is a quantitative examination to soluble RANKL (sRANKL). We used serum as the examination materials. Wells of Microtiter plate was coated by first antibody (Abnova) and incubated at $4^{\circ} \mathrm{C}$ for overnight (16-18 h). Microtiter plate was washed twice with a solution of PBST (1x PBS supplemented with $1.2 \%$ Tween-20). After that, a layer was blocked by addition of $200 \mathrm{uL}$ blocking buffer (5\% skim milk in PBST) and incubated at least $2 \mathrm{~h}$ at room temperature. Plate then washed twice using PBST. Samples were added to the plate and incubated for $2 \mathrm{~h}$ at room temperature. Furthermore, plate was washed three times with PBST.

Table 1: Primers and PCR condition

\begin{tabular}{|c|c|c|c|c|c|}
\hline Gen & Positions & SNP & Sequencing & Annealing temperature & PCR product \\
\hline$\overline{\text { RANK }}$ & Exon & rs1805034 & $\begin{array}{l}\mathrm{F}=5^{\prime} \text {-GGGGATTCAAATGTCCAAGAAGG-3' } \\
\mathrm{R}=5^{\prime} \text { - CATGCACGGGATGAAATAAAGGG-3' }\end{array}$ & $56^{\circ} \mathrm{C}$ & $353 b p$ \\
\hline RANK & Exon & rs121908659 & $\begin{array}{l}\mathrm{F}=5^{\prime} \text {-GAACTGAGATCACGCCATTG-3' } \\
\mathrm{R}=5^{\prime} \text {-GAAAGCCTCACCCACTTTTG-3' }\end{array}$ & $62^{\circ} \mathrm{C}$ & $301 b p$ \\
\hline RANKL & Promoter & rs9594759 & 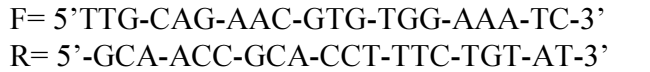 & $47^{\circ} \mathrm{C}$ & $302 \mathrm{bp}$ \\
\hline
\end{tabular}

Table 2: PCR-RFLP conditions

\begin{tabular}{|c|c|c|c|c|}
\hline SNP & Enzyme restriction & Amino acid changes & Genotype & Size \\
\hline \multirow[t]{3}{*}{ rs1805034 } & AciI & $\mathrm{Ala} \rightarrow \mathrm{Va})$ & $\mathrm{CC}$ & 188bp, 130bp, 36bp \\
\hline & & & $\mathrm{CT}$ & $316 b p, 188 b p, 130 b p, 36 b p$ \\
\hline & & & TT & 316bp, 37bp \\
\hline \multirow[t]{3}{*}{ rs121908659 } & BsaAI & Gly $\rightarrow$ Arg & GG & $301 \mathrm{pb}$ \\
\hline & & & $\mathrm{GC}$ & $301 \mathrm{bp}, 246 \mathrm{bp}, 55 \mathrm{bp}$ \\
\hline & & & $\mathrm{CC}$ & 246bp, 55bp \\
\hline \multirow[t]{3}{*}{ rs9594759 } & DdeI & - & $\mathrm{CC}$ & $236 b p, 66 b p$ \\
\hline & & & $\mathrm{CT}$ & 302bp, 236bp, 66bp \\
\hline & & & TT & $302 b p$ \\
\hline
\end{tabular}


Antibody detection solution (Biotinylated mouse $\mathrm{mAb}$ ) was added to the microtiter wells and incubated for 2 hours at room temperature. Plate was washed three times with PBST. Secondary reagents (Streptavidin-HRP) was added to the microtiterplatewells and incubated for one hour. Plate washed four times using PBST. Substrate solution was added to each microtiter well and incubated for $15 \mathrm{~min}$. The stop solution was added to microtiter plate and in less than 30 min microtiterplatemust be read using ELISA plate reader at $405 \mathrm{~nm}$ with a filter length of $630 \mathrm{~nm}$.

\section{Statistical Analysis}

Analysis on the acquired data was performed using SPSS. Chi-square was used to determine genotype/allotype association of RANK/RANKL on osteoporosis and nonosteoporosis groups. Kruskal Wallis and Mann-Whitney test were used to analyze the correlation between genotype and osteoporosis risk with sRANKL levels. The Odds Ratio (OR) was used to look at the association of gene polymorphism and the risk of osteoporosis.

\section{Results}

\section{Genotyping Analysis}

PCR technique was used to amplify the target DNA on RANK/RANKL gene that contains polymorphic sites rs121908659, rs1805034 and rs9594759. PCR result using pair of primer for RANK/RANKL yielded a single band. DNA amplicon was cut using enzyme restriction to determine genotype (Fig. 1).

Sample consists of 210 post-menopausal women's genotype and allotype were analyzed on RANK/RANKL gene. This study showed that the highest allele frequency distributions were $\mathrm{T}$ allele for rs1805034, $\mathrm{G}$ for rs121908659 and C rs9594759. In addition, no genotypes of homozygous mutant rs121908659 were found (Table 3).

Distribution of Frequency of Genotype and Allotype on Non-Osteoporosis and Osteoporosis Group

Genotype and allotype data acquired by using PCRRFLP technique were analyzed statistically. Chi-square test analysis on the frequency genotype and allotype group yielded the value of $\mathrm{p}<0.05$. From 210 postmenopausal women analyzed, frequency of genotype and allotype rs1805034 (RANK gene) and rs9594759 (RANKL gene) did not show significant differences between subgroups, whereas rs121908659 showed significant difference between subgroup. In rs121908659, CG genotype on osteoporosis group was higher than the non-osteoporosis. $C$ allotype on osteoporosis group were higher than the nonosteoporosis. This indicates that the CG genotype group was more prone to osteoporosis compared with the GG genotype group. Mutant homozygote CC genotype was not found on either group. Frequency distributions of RANK/RANKL gene between subgroup are shown in Table 4.

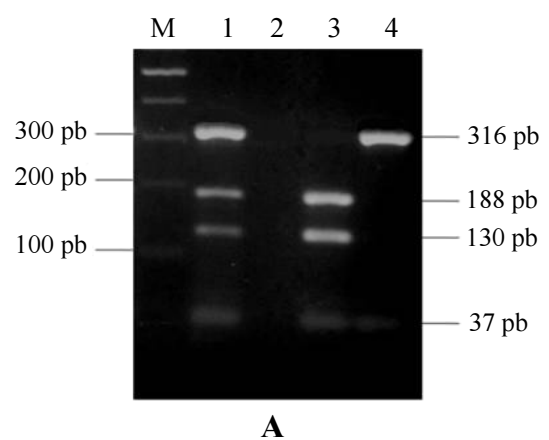

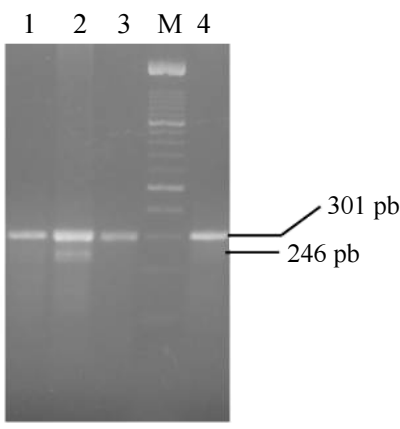

B

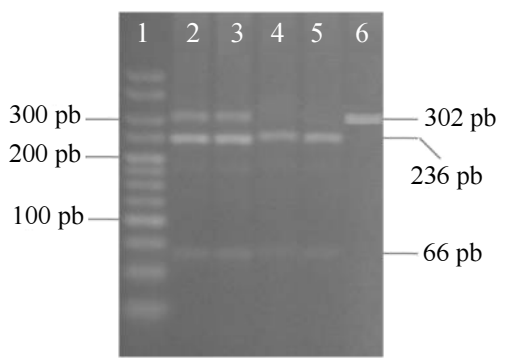

C

Fig. 1: Agarose gel electrophoresis of PCR-RFLP for RANK and RANKL genotypes analysis. The samples were electrophoresed against 100bp DNA ladder. Genotypes were labeled on the gel. (A) RANK (rs1805034) genotypes analysis, Line $1=\mathrm{CT}$, line $3=\mathrm{CC}$, line $4=\mathrm{TT}, \mathrm{B}$ ) RANK (rs121908659) genotypes analysis, line 1,3,4 = GG, line $2=\mathrm{GC}, \mathrm{C}$ ) RANKL rs9594759 genotypes analysis, line 2-3 $=\mathrm{CT}$, line $4-5=\mathrm{CC}$ and line $6=\mathrm{TT}$

Table 3: Frequency distribution of genotype and allotype in postmenopausal Indonesian woman

\begin{tabular}{|c|c|c|c|c|c|}
\hline \multicolumn{3}{|c|}{ Genotype } & \multicolumn{3}{|c|}{ Allotype } \\
\hline RANK (rs1805034) & $\mathrm{CC}=6 \%$ & $\mathrm{CT}=36 \%$ & $\mathrm{TT}=58 \%$ & $\mathrm{C}=24 \%$ & $\mathrm{~T}=76 \%$ \\
\hline RANK (rs121908659) & $\mathrm{CC}=0 \%$ & $\mathrm{CG}=\mathbf{8 \%}$ & $\mathrm{GG}=92 \%$ & $\mathrm{C}=4 \%$ & $G=96 \%$ \\
\hline RANKL (rs9594759) & $\mathrm{CC}=48 \%$ & $\mathrm{CT}=36 \%$ & $\mathrm{TT}=16 \%$ & $C=66 \%$ & $\mathrm{~T}=34 \%$ \\
\hline
\end{tabular}


Table 4: Association genotype and allotype with osteoporosis in postmenopausal Indonesian woman

\begin{tabular}{|c|c|c|c|c|}
\hline & Osteoporosis & Non-osteoporosis & $\mathrm{p}$ & OR \\
\hline \multicolumn{5}{|c|}{ RANK (rs1805034) } \\
\hline Genotype & $7 \%$ & $5 \%$ & \multirow{3}{*}{$\mathrm{p}>0.05$} & $\mathrm{CT}$ vs $\mathrm{CC}=0.64(0.19-2.2), \mathrm{p}>0.05$ \\
\hline $\mathrm{CC}$ & $34 \%$ & $38 \%$ & & TT vs $\mathrm{CT}=1.16(0.64-2.08), \mathrm{p}>0.05$ \\
\hline $\mathrm{CT}$ & $59 \%$ & $57 \%$ & & TT vs $\mathrm{CC}=0.74(0.22-2.46), \mathrm{p}>0.05$ \\
\hline \multicolumn{5}{|l|}{ TT } \\
\hline \multicolumn{5}{|l|}{ Allotype } \\
\hline $\mathrm{C}$ & $24 \%$ & $24 \%$ & \multirow[t]{2}{*}{$\mathrm{p}>0.05$} & \multirow{2}{*}{$\mathrm{C}$ vs $\mathrm{T}=1(0.52-1.91), \mathrm{p}>0.05$} \\
\hline $\mathrm{T}$ & $76 \%$ & $76 \%$ & & \\
\hline \multicolumn{5}{|c|}{ RANK (rs121908659) } \\
\hline Genotype & $0 \%$ & $0 \%$ & \multirow{3}{*}{$\mathrm{p}<0.05$} & NA \\
\hline $\mathrm{CC}$ & $13 \%$ & $3 \%$ & & CG vs GG $=4.83(1.33-17.52), p<0.05$ \\
\hline $\mathrm{CG}$ & $87 \%$ & $97 \%$ & & NA \\
\hline \multicolumn{5}{|l|}{ GG } \\
\hline \multicolumn{5}{|l|}{ Allotype } \\
\hline $\mathrm{C}$ & $6.5 \%$ & $1.5 \%$ & \multirow[t]{2}{*}{$\mathrm{p}<0.05$} & \multirow[t]{2}{*}{$\mathrm{C}$ vs $\mathrm{G}=4.57(2.59-8.06), \mathrm{p}<0.05$} \\
\hline G & $93.5 \%$ & $98.5 \%$ & & \\
\hline \multicolumn{5}{|c|}{ RANKL (rs9594759) } \\
\hline Genotype & $51 \%$ & $39 \%$ & \multirow[t]{3}{*}{$\mathrm{p}>0.05$} & CT vs $\mathrm{CC}=0.52(0.28-0.97), \mathrm{p}<0.05$ \\
\hline $\mathrm{CC}$ & $30 \%$ & $44 \%$ & & TT vs $\mathrm{CT}=1.64(0.73-3.66), \mathrm{p}>0.05$ \\
\hline $\mathrm{CT}$ & $19 \%$ & $17 \%$ & & TT vs $\mathrm{CC}=0.85(0.39-1.86), \mathrm{p}>0.05$ \\
\hline \multicolumn{5}{|r|}{ 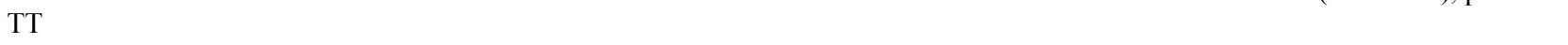 } \\
\hline \multicolumn{5}{|l|}{ Allotype } \\
\hline $\mathrm{C}$ & $66 \%$ & $61 \%$ & $\mathrm{p}>0.05$ & $\mathrm{C}$ vs $\mathrm{T}=1.24(0.70-2.21), \mathrm{p}>0.05$ \\
\hline $\mathrm{T}$ & $34 \%$ & $39 \%$ & & \\
\hline
\end{tabular}

Table 5: Level of sRANKL in postmenopausal Indonesian woman

\begin{tabular}{lll}
\hline & sRANKL & $\mathrm{p}$ \\
\hline Genotype & & \\
CC & $0.119 \pm 0.028 \mathrm{a}$ & \\
CT & $0.190 \pm 0.034 \mathrm{~b}$ & $\mathrm{p}<0.05$ \\
TT & $0.191 \pm 0.034 \mathrm{~b}$ & \\
Group of Non-Osteoporosis & $0.153 \pm 0.028 \mathrm{a}$ & $\mathrm{p}>0.05$ \\
Osteoporosis & $0.176 \pm 0.039 \mathrm{a}$ & \\
\hline
\end{tabular}

Along with Chi-square analysis, odd ratio analysis was also performed to determine the risk of genotype group against osteoporosis. Odd ratio analysis result showed that CG genotype in RANK gene (rs121908659) has osteoporosis risk of 4.83 times higher than the GG genotype group. This shows that individual with $\mathrm{CG}$ genotype is more prone to osteoporosis with 4.83 fold than GG genotype. CG genotype is not always going to manifest on osteoporosis because osteoporosis is a multifactor disease. Osteoporosis can manifest not only because of the genetic factor, but also the environmental factors. In RANKL gene (rs9594759) showed that CT genotype has osteoporosis protective of 1.92 times higher than CC genotype, even though genotype and allotype RANKL gene have no association between osteoporosis and non-osteoporosis group.

Our result showed that the high sRANKL levels in CT and TT genotypes compare with CC genotype (Table 5). Statistical analysis was performed using Kruskal-Willis test because the data obtained had abnormal distribution. The results of statistical analysis obtained $\mathrm{p}$ value $=0.027$. Because the $\mathrm{p}$ value is less than 0.05 , the sRANKL levels differ significantly in the genotype group. The sRANKL levels in the TT and CT genotypes were not significantly different, but they were significantly different from the sRANKL levels in the CC genotype.

\section{Discussion}

Mutation of rs121908659 has a recessive autosomal property. It is reported that homozygote mutation is found on osteopetrosis sufferers, on boys or girls. Those osteopetrosis sufferers were born from heterozygote genotype parents (Guerrini et al., 2008). In this research, the data of frequency of genotype distribution shows no mutant homozygote, therefore it supported the notion that the mutation is recessive autosomal and gives clinical manifestation effect since childhood, because it is not found on physiologically normal population on older age group.

Mutation on rs121908659 transformed the Glyamino acid into Arg amino acid. Glyis an amino acid with isoelectric point on 5.97 (non-polar, aliphatic residues), while Arghas isoelectric point on 10.76 (positively charged residues). Transformation of Glyamino acid into Argchanges the isoelectric point, which in turn influences protein structure transformation. The mutation on this point are on the extracellular domain, on the ligand bonding site, therefore the transformation in RANK structure can influence bonding affinity between RANK and RANKL. 
Transformation of Gly into Arg on heterozygote genotype causes the increase on osteoporosis risk. From that point we can assume that the transformation of Gly into Arg will cause transformation on RANK protein structure, which in turn will increase the bonding affinity between RANK and RANKL. This will cause the increase of osteoclastogenesis process. The increase of osteoclast production will in turn increase the bone absorption process, which will decrease the bone density. Therefore, the mutation on rs121908659 is associated with osteoporosis risk on post-menopausal women in Indonesia.

The osteoporosis group had the highest sRANK levels than non-osteoporosis group in post menopausal Indonesian women. Statistical analysis was performed by using Kruskal Wallis test because data was not a normal distribution. It showed that SRANKL levels was not significant in the subgroup (osteoporosis and nonosteoporosis) with $\mathrm{p}$ value of 0.59 .

Measurements of SRANKL with elisa technique showed sRANK levels in CC genotype has significantly lower than CT and TT genotypes. RANKL is a cytokine that plays an important role in osteoclastogenesis. Increased RANKL will lead to increased osteoclast cells, thereby enhancing the bone absorption process. Subsequently, this will lead to the decrease in bone density. TT genotype has high sRANKL levels. It shows that the osteoclastogenesis process will be high and increase bone resorption. RANKL have three isoform. Isoforms 1 and 3 are trans-membrane, while the isofom 2 has a soluble form. Increased sRANKL levels generally provide pathological effects, whereas increased transmembrane RANKL isoforms have more effect on physiological changes. The process of osteoporosis in post-menopausal women is more due to the physiological changes resulting from estrogen deficiency.

A study on rs9594759 by Roshandel et al. (2010) showed that (In a study conducted by Roshandel et al. (2010) that analysed rs9594759 reported that) C alleles have higher BMD ultrasound than $\mathrm{T}$ alleles (Roshandel et al., 2010). This is consistent with the results of our study, where $\mathrm{C}$ allele has lower sRANKL levels than $\mathrm{T}$ alleles that can result in lower osteoclast formation process. In the European population $\mathrm{T}$ alleles have a higher risk of osteoporosis compared to the $\mathrm{C}$ allele which is a minor allele in the European population. Mutation in rs9594759 might be resulting in an increase in the sRANKL levels caused by enhancement of enhancer activity in the RANKL gene.

In our study on Indonesian population showed that frequency of $\mathrm{C}$ alleles was higher in osteoporotic menopausal women. This result is different from the results in Europe population. Our study suggests that the process of osteoporosis in postmenopausal women that occurs in the Indonesian population is more affected by the low mineralization process and bone formation. Osteoporosis is not only influenced by sRANKL levels, but also by many factors, among others: nutritional intake, healthy lifestyle, hormonal contraceptive use, or other gene activity. One of the genes that need to be analyzed is the Vitamin D Receptor (VDR) because the RANKL mutation in this study resides in the RANKL enhancer gene element that is activated by attachment of the VDR complex. Therefore, it is necessary to analyze whether there is a linkage between polymorphism of RANKL enhancer elements with VDR polymorphism in the population.

\section{Conclusion}

RANK and RANKL have a role in the risk of osteoporosis in postmenopausal women in Indonesia. RANK genotypes and allotypes (rs121908659) were associated with an increased risk of osteoporosis, whereas RANKL heterozygotes shown protective factors of osteoporosis. Mutations in the RANKL gene was associated with increased sRANKL levels.

\section{Funding Information}

We would like to thank DRPM which has provided research funding through "Program Hibah Riset Awal UI.

\section{Author Contributions}

All authors contributed equally in this work.

\section{Conflicts of Interest}

There are no conflicts of interest.

\section{Ethics}

The authors declare that this article is original and has received permission from Research Ethics Committee of Faculty of Medicine University Indonesia (Approval letter No. 159/H2.F1/ETIK/2013).

\section{References}

Bell, N., 2003. RANK ligand and the regulation of skeletal remodeling. J. Clin. Invest., 111: 1120-1122. DOI: $10.1172 / \mathrm{JCI} 18358$

Bitto, A., B.P. Burnett, F. Polito, H. Marini and R.M. Levy et al., 2008. Effects of genistein aglycone in osteoporotic, ovariectomized rats: A comparison with alendronate, raloxifene and oestradiol. Br. J. Pharmacol., 155: 896-905. DOI: $10.1038 /$ bjp.2008.305

Bonfá, A.C., L.P.C. Seguro, V. Caparbo, E. Bonfá and R.M.R. Pereira, 2015. RANKL and OPG gene polymorphisms: Associations with vertebral fractures and bone mineral density in premenopausal systemic lupus erythematosus. Osteoporos Int., 26: 1563-1571. DOI: $10.1007 / \mathrm{s} 00198-015-3029-\mathrm{x}$ 
Boyle, W., W.S. Simonet and D.L. Lacey, 2003. Osteoclast differentiation and activation. Nature, 423: 337-342. DOI: 10.1038/nature01658

Eghbali-Fatourechi, G., S. Khosla, A. Sanyal, W.J. Boyle and D.L. Lacey et al., 2003. Role of RANK ligand in mediating increased bone resorption in early postmenopausal women. J. Clin. Invest., 9: 83-89. DOI: 10.1172/JCI200317215

Finkelstein, J., S.E. Brockwell, V. Mehta, G.A. Greendale and M.F.R. Sowers et al., 2008. Bone mineral density changes during the menopausal transition in a multiethnic cohord of women. J. Clin. Endocrinol. Metab., 93: 861-868. DOI: $10.1210 /$ jc. $2007-1876$

Giroux, S. and F. Rousseau, 2009. Genes and osteoporosis: Time for a change in strategy. Int. J. Clin. Rheumato., 4: 221-233. DOI: $10.2217 /$ ijr.09.11

Guerrini, M., C. Sobacchi, B. Cassani, P. Vezzoni and A. Villa et al., 2008. Human osteoclast-poor osteopetrosis with hypogammaglobulinemia due to TNFRSF11A (RANK) mutations. Am. J. Hum. Genet., 83: 64-76. DOI: 10.1016/j.ajhg.2008.06.015

Jilka, L., 2001. Cell biology of osteoclast and osteoblast and the hormone and cytokinesis that control their development and activity. Proceedings of the $1 \mathrm{st}$ Join Meeting of the International Bone and Mineral Society and the European Calcified Tissue Society, Madrid, Spain.

Jones, D., Y. Kong and J. Penninger, 2002. Role of RANKL and RANK in bone loss and arthritis. Annals Rheumatic Dis., 61: ii32-ii39. DOI: 10.1136/ard.61.suppl 2.ii32

Kearns, A., S. Khosla and P. Kostenuik, 2008. Receptor activator of nuclear factor $\mathrm{kB}$ ligand and osteoprotegerin regulation of bone remodeling in health and disease. Endocrinol. Rev., 29: 155-192. DOI: 10.1210/er.2007-0014

Koh, J.M., B.L. Park, D.J. Kim, G.S. Kim and H.S. Cheong et al., 2007. Identification of novel RANK polymorphisms and their putative association with low BMD among postmenopausal women. Osteoporosis Int., 18: 323-331.

DOI: $10.1007 / \mathrm{s} 00198-006-0244-5$

Lacey, D., E. Timms H.L. Tan, J. Guo and J. Delaney et al., 1998. Osteoprotegerin ligand is a cytokine that regulates osteoclast differentiation and activation. Cell, 93: 165-176.

DOI: $10.1016 / \mathrm{S} 0092-8674(00) 81569-\mathrm{X}$
Manolagas, S.C., 2000. Birth and death of bone cells: Basic regulatory mechanisms and implications for the pathogenesis and treatment of osteoporosis. Endocrine Rev., 21: 115-137. DOI: $10.1210 /$ er.21.2.115

McClung, M., 2007. Role of RANKL inhibition in osteoporosis. Arthr. Res. Ther., 9: 83-89. DOI: $10.1186 / \operatorname{ar} 2167$

Nelson, H.D., 2008. Menopause. Lancet, 371: 760-770. DOI: $10.1016 / \mathrm{S} 0140-6736(08) 60346-3$

Raisz, L.G., 2005. Pathogenesis of osteoporosis: Concepts, conflicts and prospects. J. Clin. Invest., 115: 3318-3325. DOI: 10.1172/JCI27071

Roshandel, D., K.L. Holliday, S.R. Pye, S. Boonen and H. Borghs et al., 2010. Genetic variation in the RANKL/RANK/OPG signaling pathway is associated with bone turnover and bone mineral density in men. J. Bone Mineral Res., 25: 1830-1838. DOI: $10.1002 / \mathrm{jbmr} .78$

Rubin, J. and E. Greenfield, 2005. Osteoclast: Origin and Differentiation. In: Bronner, F., M.C. Farach-Carson and J. Rubin (Eds.), Bone Respiration, Springer, Verlag London, pp: 1-16.

Srivastava, S., G. Taraldo and M. Weitzmann, 2001. Estrogen decreases osteoclast formation by downregulating Receptor Activator of NF-kB Ligand (RANKL)-induced JNK activation. J. Bio. Chem., 34: 234-245.

Styrkarsdottir, U., B.V. Halldorsson, S. Gretarsdottir, D.F. Gudbjartsson and G.B. Walters et al., 2008. Multiple genetic loci for bone mineral density and fractures. N Engl. J. Med., 358: 235-265. DOI: 10.1056/NEJMoa0801197

Teitelbaum, S.L., 2004. Postmenopausal osteoporosis, T cells and immune dysfunction. Proc. Nat. Acad. Sci. USA, 101: 16711-16712. DOI: $10.1073 /$ pnas.0407335101

Tu, P., P. Duan, R.S. Zhang, D.B. Xu and Y. Wang et al., 2015. Polymorphisms in genes in the RANKL/RANK/OPG pathway are associated with bone mineral density at different skeletal sites in post-menopausal women. 179-185. DOI: $10.1007 / \mathrm{s} 00198-014-2854-7$

Wang, F., Y. Cao, F. Li, J. Shan and T. Wen, 2014. Association analysis between g. $18873 \mathrm{C}>\mathrm{T}$ and $\mathrm{g}$. $27522 \mathrm{G}>$ a genetic polymorphisms of OPG and bone mineral density in Chinese postmenopausal women. Biomed Res. Int., 2014: 1-5. DOI: $10.1155 / 2014 / 320828$

Weitzmann, M. and R. Pacifici, 2006. Estrogen deficiency and bone loss: An inflammatory tale. J. Clin. Invest., 116: 1186-1194.

DOI: $10.1172 / \mathrm{JCI} 28550$ 